\title{
Primary Prevention of Stroke in Chronic Kidney Disease Patients: A Scientific Update
}

\author{
Stefana Catalina Bilha ${ }^{a}$ Alexandru Burlacu $^{a}$ b Dimitrie Siriopol $^{a, c}$ \\ Luminita Voroneanu ${ }^{a, c}$ Adrian Covic ${ }^{a, c}$ \\ a Department of Nephrology, "Grigore T. Popa” University of Medicine and Pharmacy, lasi, Romania; b Department \\ of Interventional Cardiology, Cardiovascular Diseases Institute, Iasi, Romania; ' Nephrology Clinic, Dialysis and Renal \\ Transplant Center, "C.I. Parhon" University Hospital, Iasi, Romania
}

\section{Keywords}

Primary prevention $\cdot$ Stroke $\cdot$ Chronic kidney disease

\begin{abstract}
Background: Although chronic kidney disease (CKD) is an independent risk factor for stroke, official recommendations for the primary prevention of stroke in CKD are generally lacking. Summary: We searched PubMed and ISI Web of Science for randomised controlled trials, observational studies, reviews, meta-analyses and guidelines referring to measures of stroke prevention or to the treatment of stroke-associated risk factors (cardiovascular disease in general and atrial fibrillation (AF), arterial hypertension or carotid artery disease in particular) among the CKD population. The use of oral anticoagulation in AF appears safe in non-end stage CKD, but it should be individualized and preferably based on thromboembolic and bleeding stratification algorithms. Non-vitamin $\mathrm{K}$ antagonist oral anticoagulants with definite dose adjustment are generally preferred over vitamin $\mathrm{K}$ antagonists in mild and moderate CKD and their indications have started being extended to severe CKD and dialysis also. Aspirin, but not clopidogrel, has limited indications for reducing the risk for atherothrombotic events in CKD due to its increased bleeding risk. Carotid endarterectomy has shown promising
\end{abstract}

\section{KARGER}

(C) 2018 S. Karger AG, Basel

E-Mail karger@karger.com

www.karger.com/ced results for stroke risk reduction in CKD patients with highgrade symptomatic carotid stenosis. The medical treatment of arterial hypertension in CKD often fails to efficiently lower blood pressure values, but recent data regarding the use of interventional procedures such as renal denervation, baroreflex activation therapy or renal artery stenting are encouraging. Key Messages: In the absence of clear guidelines and protocols, primary prevention of stroke in CKD patients remains a subtle art in the hands of the clinicians. Nevertheless, refraining CKD patients from standard therapies often worsens their prognosis.

(c) 2018 S. Karger AG, Basel

\section{Background}

Chronic kidney disease (CKD) has been recognized by the American Heart Association as an independent risk factor for stroke [1]. The incidence of stroke is indeed disproportionately higher in CKD patients and especially in end-stage renal disease (ESRD): $14.9-49$ per 1,000 person-years in ESRD [2,3] compared to 0.41-2.38 per 1,000

Alexandru Burlacu

Department of Interventional Cardiology

Cardiovascular Diseases Institute, No. 50 Carol I Blvd.

Iasi 700503 (Romania)

Department of Nephrology

"Grigore T. Popa" University of Medicine and Pharmacy

No. 16 University Street, Iasi 700115 (Romania)

E-Mail alburlacu@yahoo.com 
Fig. 1. Practical clinical dilemmas in the management of primary stroke prevention in chronic kidney disease. CEA, carotid endarterectomy; CAS, carotid angioplasty and stenting; PTRA, percutaneous transluminal renal angioplasty.

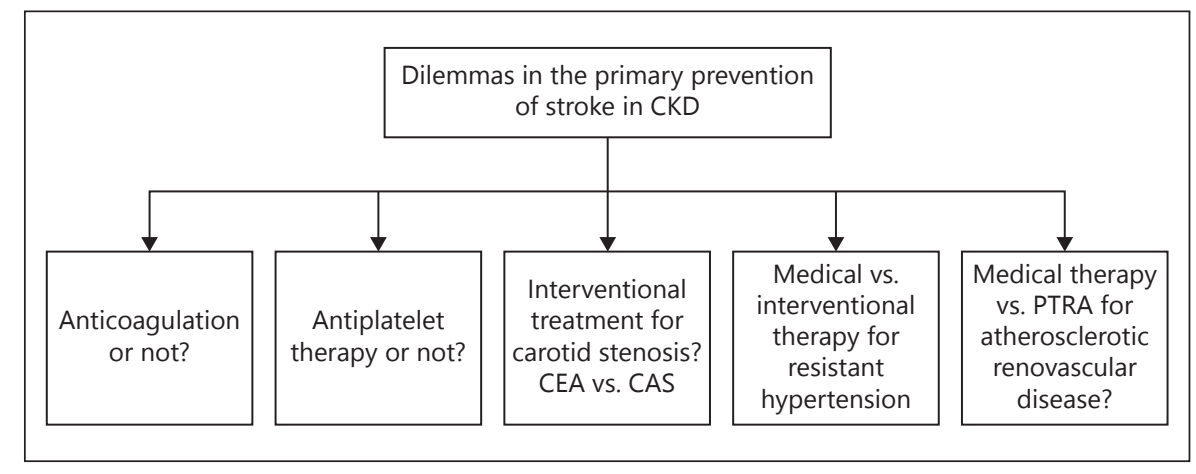

persons/year in the general population worldwide [4]; concurrently, stroke may cause renal impairment [5] and figures describing the 2-way "cerebro-renal" relationship are similar: CKD stage 3 or higher increases the risk for stroke by $43 \%$ [6], while post- (ischaemic) stroke kidney dysfunction occurs in up to $40 \%$ stroke survivors among the general population [5].

Nevertheless, measures for preventing a first stroke are often difficult to input in CKD due to the lack of sufficient data: guidelines are poor in giving recommendations in this population and thus clinicians frequently face significant dilemmas such as the decision to use anticoagulation or antiplatelet agents, to choose between medical and interventional management or to choose between 2 different types of interventional procedures that pose considerable risks, and so on (Fig. 1).

This review will discuss the newest evidence-based approaches for preventing a first stroke in CKD; emphasis will be made on specific conditions highly prevalent in CKD that majorly impact the risk for stroke (e.g., atrial fibrillation-AF, carotid atherosclerosis and resistant hypertension- $\mathrm{RH}$ ) but raise great concern regarding their management. For the clarity of the scientific approach, this article is structured according to the type of stroke in general (ischaemic and haemorrhagic), in the setting of CKD. The ischaemic stroke section discusses the 2 major causes (cardioembolic and atherothrombotic), and the haemorrhagic stroke section tackles treatment-RH and bleeding on antithrombotic therapy.

\section{Methods}

We searched the electronic databases of PubMed and ISI Web of Science from inception until September 13, 2017 using the search terms "primarypreventionandstroke"/"atrialfibrillation"/"resistant hypertension"/“cardiovascular disease"/“carotid"/"peripheral artery disease" and "chronic kidney disease"/"dialysis," with and with- out "guidelines." Randomised controlled trials (RCTs), observational studies, reviews, meta-analyses and guidelines were included if measures of stroke prevention or to the treatment of stroke-associated risk factors (cardiovascular disease [CVD] in general and AF, arterial hypertension or carotid/peripheral artery disease in particular) were first referred to in the CKD population; if highly relevant or if CKD data were very scarce or lacking, data regarding the general population was also referred to. Relevant references from the selected articles and guidelines were also searched manually afterwards.

\section{Ischaemic Stroke}

\section{Cardioembolic Stroke: AF}

CKD patients with AF (approximately a quarter of all renal patients) [7] are more prone to experiencing both stroke and bleeding, which makes the use of oral anticoagulants a subtle art in managing stroke risk in this population (Tables 1, 2) $[8,9]$.

\section{Non-ESRD Patients}

Anticoagulation is safe for an estimated glomerular filtration rate $(\mathrm{eGFR}) \geq 15 \mathrm{~mL} / \mathrm{min} / 1.73 \mathrm{~m}^{2}$, according to the 2016 European Society of Cardiology (ESC) guidelines for the management of AF [10].

There is currently no restriction in using vitamin $\mathrm{K}$ antagonists (VKA) in non-ESRD CKD [11]. The classic treatment of AF with VKA (namely warfarin) significantly reduces the risk of stroke in non-end stage CKD, without significantly impacting the risk for major bleeding [12]. VKA have a renal elimination of only $10-15 \%$ [13]; however, a creatinine clearance under $30 \mathrm{~mL} / \mathrm{min}$ was shown to be an independent predictor of warfarin-associated haemorrhagic risk [14] and therefore, careful dose titration is needed in patients with advanced kidney impairment [13]. This observation is also supported by a 2017 research, which demonstrated that severe non-ESRD 
Table 1. NOACs use in AF and CKD: dosage and administration according to EMA and FDA

\begin{tabular}{|c|c|c|c|c|c|}
\hline & & Dabigatran & Rivaroxaban & Apixaban & Edoxaban \\
\hline $\begin{array}{l}\mathrm{eGFR} \geq 50 \mathrm{~mL} / \mathrm{min} \\
(\mathrm{CKD} 1-3 \mathrm{~A})\end{array}$ & $\begin{array}{l}\text { EMA } \\
\text { FDA }\end{array}$ & $150 \mathrm{mg}$ twice daily & $20 \mathrm{mg}$ once daily & $5 \mathrm{mg}$ twice daily & $60 \mathrm{mg}$ once daily \\
\hline $\begin{array}{l}\text { eGFR }=15-49 \\
\mathrm{~mL} / \mathrm{min} \\
(\mathrm{CKD} 3 \mathrm{~B}-4)\end{array}$ & EMA & \multicolumn{2}{|c|}{$\begin{array}{l}30-49 \mathrm{~mL} / \mathrm{min}: 150 \mathrm{mg} 15 \mathrm{mg} \text { once daily } \\
\text { or } 110 \mathrm{mg} \text { twice daily if } \\
\text { high bleeding risk } \\
15-29 \mathrm{~mL} / \mathrm{min}: \mathrm{NR}\end{array}$} & $\begin{array}{l}30-49 \mathrm{~mL} / \mathrm{min}: \text { Reduce to } 2.5 \mathrm{mg} \\
\text { twice daily if } 2 \text { of: } \\
\text { - Creatinine } \geq 1.5 \mathrm{mg} / \mathrm{dL} \\
\text { - Age } \geq 80 \text { years } \\
\text { - Body weight } \leq 60 \mathrm{~kg} \\
15-29: 2.5 \mathrm{mg} \text { twice daily } \\
\text { Reduce to } 2.5 \mathrm{mg} \text { twice daily if } 2 \text { of: } \\
\text { - Creatinine } \geq 1.5 \mathrm{mg} / \mathrm{dL} \\
\text { - Age } \geq 80 \text { years } \\
\text { - Body weight } \leq 60 \mathrm{~kg}\end{array}$ & $30 \mathrm{mg}$ once daily \\
\hline $\begin{array}{l}\text { eGFR }<15 \mathrm{~mL} / \mathrm{min} \\
\text { (CKD } 5 \text { and dialysis) }\end{array}$ & $\begin{array}{l}\text { EMA } \\
\text { FDA }\end{array}$ & NR & $\begin{array}{l}\text { NR } \\
15 \text { mg once daily }\end{array}$ & $\begin{array}{l}\text { NR } \\
\text { Reduce to } 2.5 \mathrm{mg} \text { twice daily if: } \\
\text { - Age } \geq 80 \text { years or } \\
\text { - Body weight } \leq 60 \mathrm{~kg}\end{array}$ & NR \\
\hline
\end{tabular}

Adapted from Burlacu et al. [9] and according to prescribing information for dabigatran, rivaroxaban, apixaban and edoxaban available at http://www.ema.europa.eu and www.accessdata.fda.gov.

CKD, chronic kidney disease; EMA, European Medicines Agency; FDA, Food and Drug Administration; NOACs, non-vitamin K antagonist oral anticoagulants, NR, not recommended.

CKD patients treated with warfarin have a labile international normalized ratio with a significantly lower time-intherapeutic range and a higher adverse events risk [15].

The novel non-vitamin $\mathrm{K}$ antagonist oral anticoagulants (NOACs) are associated with lower risks for stroke and major bleeding compared to warfarin in patients with mild and moderate renal impairment [16]. Nonetheless, definite dose adjustment is needed as they have variable renal elimination (Table 1) [10]. The 2016 ESC guidelines do not support the use of NOACs in CKD stages 4 and 5 due to the lack of evidence [10], but the European Medicines Agency and the Food and Drug Administration also spread the indications to CKD stage 4 based on pharmacokinetic studies (Table 1) [9].

\section{ESRD Patients}

In the absence of RCTs regarding stroke prevention in dialysis patients with AF, the decision to use oral anticoagulants should be made on an individual basis [11]. The National Kidney Foundation-Kidney Disease Outcomes Quality Initiative (NKF-KDOQI) controversies report published in September 2017 is the first official taskforce that discusses the existing observational studies that examine warfarin use and associated stroke and bleeding risks in adults with CKD-5D and AF [17]. Strict monitor- ing due to the increased bleeding risk is mandatory (the KDOQI clinical practice guidelines for CVD in dialysis patients) [18].

Warfarin was reported to increase the risk of major bleeding by $30 \%$ in ESRD without having any effect on the risk of stroke [12]. Since the ESC and the European Medicines Agency do not support the use of NOACs in ESRD due to lack of sufficient data (Table 1) $[9,10]$ and there are no RCTs of NOACs in patients with severe CKD, warfarin still remains the only choice for oral anticoagulation [10]. Nonetheless, Food and Drug Administration supplemented the indications for apixaban and low dose of rivaroxaban usage in dialysis patients based on pharmacokinetic and pharmacodynamic studies (Table 1) $[9,19]$.

\section{Ischaemic and Bleeding Risk Stratification}

The use of individualized stratification models should be encouraged as refraining CKD patients from standard therapies ("therapeutic nihilism") worsens their prognosis $[9,20]$.

Reinecke et al. [20] have proposed a stratification algorithm for CKD patients (Fig. 2) to better identify those that would mostly benefit from anticoagulation: if [1] $\mathrm{CHADS}_{2}$ score (Congestive heart failure, Hypertension, age $\geq 75$ years, Diabetes mellitus, Stroke [double weight]) 
Table 2. Primary prevention of stroke in CKD: dilemmas

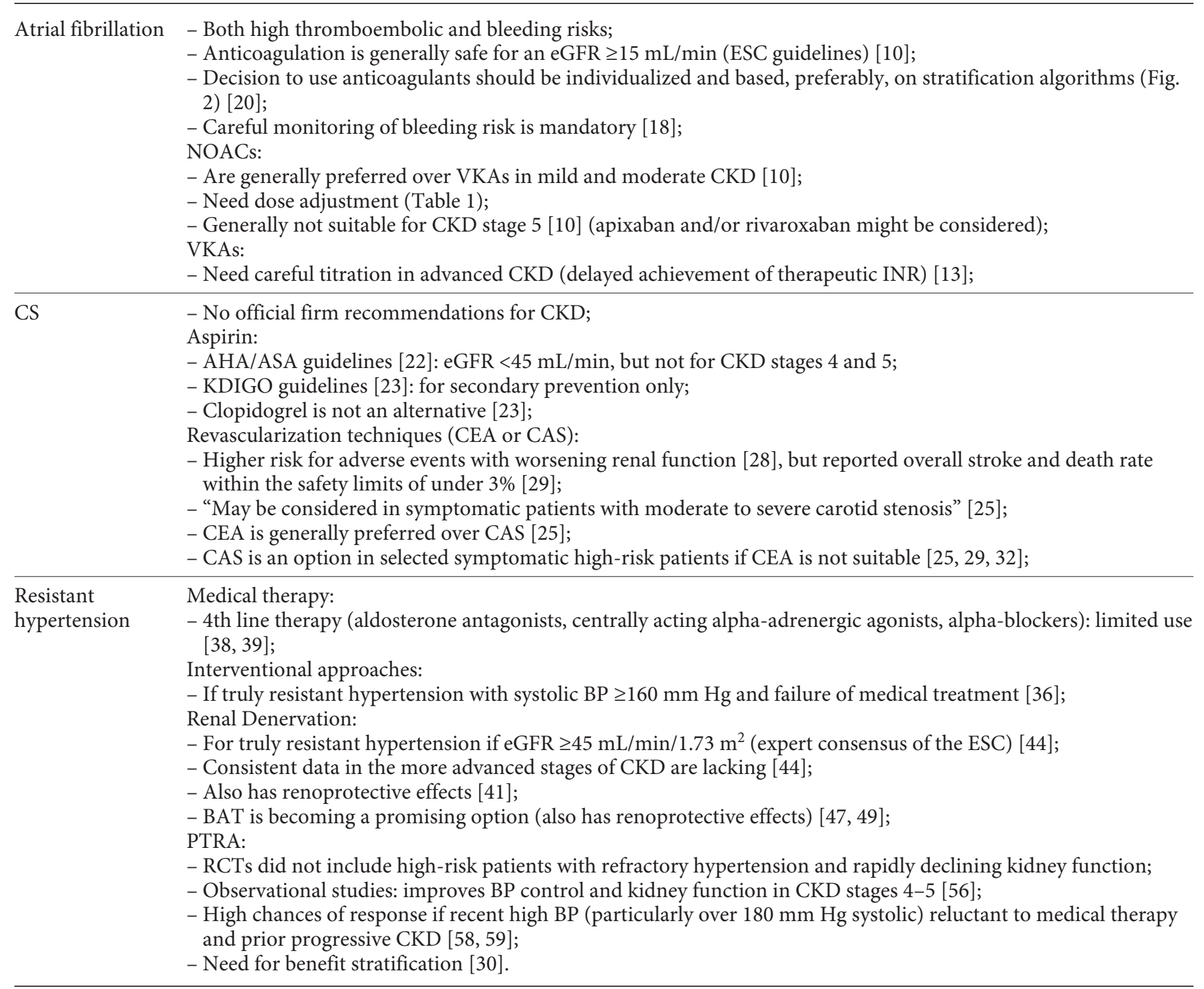

AHA/ASA, American Heart Association/American Stroke Association; ACEi, angiotensin-converting enzyme inhibitors; ARB, angiotensin II receptor blocker; BAT, baroreflex activation therapy; BP, blood pressure; CAS, carotid angioplasty and stenting; CEA, carotid endarterectomy; CKD, chronic kidney disease; CS, carotid stenosis; eGFR, estimated glomerular filtration rate; INR, international normalised ratio; KDIGO, Kidney Disease Improving Global Outcomes; NOAC, non-vitamin K antagonist oral anticoagulants; PTRA, percutaneous transluminal renal angioplasty; RAS, renal artery stenosis; RCTs, randomized controlled trials; VKA, vitamin K antagonist.

$\geq 2$ or [2] under 2 but age $\geq 75$ or [3] $\geq 1$ and age between 65 and 74 years/female sex/vascular heart disease, bleeding risk should be calculated (HAS-BLED score -Hypertension, Abnormal renal and liver function, Stroke, Bleeding Labile international normalized ratio, Elderly, Drugs or alcohol - with recurrent falls, dementia and cancer as additional factors) for the opportunity of oral anti- coagulation; if the bleeding risk is low-to-intermediate (HAS-BLED $=0-2$ ), then anticoagulation with NOAC or VKA is proposed [20].

\section{Atherothrombotic Stroke: Carotid Stenosis}

CKD patients display advanced carotid atherosclerosis with more frequently unstable or ruptured plaques due to 


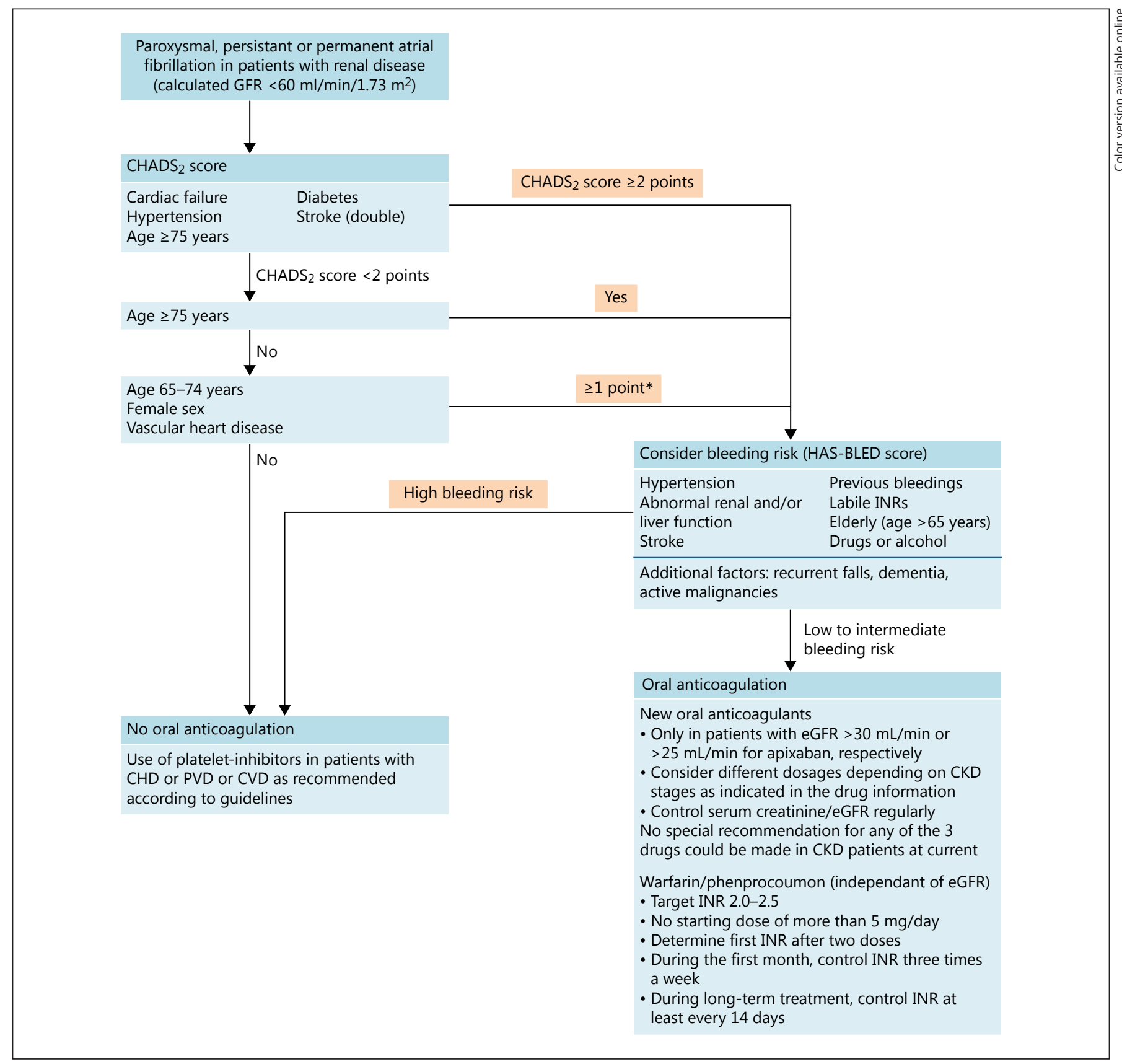

Fig. 2. Risk stratification algorithm for anticoagulation in CKD according to Reinecke et al. [20] (reproduced with permission of the publisher. ${ }^{\odot}$ Stroke, Lippincott Williams and Wilkins 2013). CKD, chronic kidney disease; CVD, cerebrovascular disease; eGFR, esti-

composition changes (less collagen, more calcified) and this explains the 3-fold higher prevalence of remote cerebrovascular events in these patients compared to non-CKD [21].

Specific guidelines for the medical treatment of carotid stenosis (CS) in CKD do not exist. The American Heart mated glomerular filtration rate; INR, international normalized ratio; PVD, peripheral vascular disease; NOACs, non-vitamin K antagonist oral anticoagulants; VKAs, vitamin K antagonists.

Association/American Stroke Association guidelines allow the use of aspirin for preventing a first stroke when eGFR is under $45 \mathrm{~mL} / \mathrm{min} / 1.73 \mathrm{~m}^{2}$, but not for CKD stages 4 and 5 [22]; at the same time, the Kidney Disease Improving Global Outcomes (KDIGO) 2012 guidelines sug- 
gest prescribing aspirin to CKD patients "at risk for atherosclerotic events" only for secondary prevention and if there is no increased bleeding risk [23] (Table 2). Antiplatelet drugs increase the risk for major and minor bleeding (by 33 and 49\%, respectively) but do not significantly reduce the risk for stroke, all-cause and cardiovascular mortality [24]. Clopidogrel is generally not a practicable alternative to aspirin: it brings no benefits over placebo for reducing stroke risk in $\mathrm{CKD}$, possibly due to an occurring clopidogrel resistance [23].

European guidelines (ESC) do not address the puzzle of carotid endarterectomy (CEA) and carotid angioplasty and stenting (CAS) in CKD patients; the North American Society for Vascular Surgery Guidelines state that "among asymptomatic patients with cardiac or renal insufficiency, best medical therapy may be preferable to CAS or CEA," while "CEA or CAS may be considered among symptomatic high-risk patients with moderate to severe CS” [25].

Clinical trials investigating CEA or CAS in CKD are missing, but retrospective studies have shown that worsening renal function is generally associated with an increased risk of myocardial infarction, stroke and death after both CEA (9\% for CKD vs. $2.6 \%$ for controls 30 days after CEA) [26] and CAS (hazard ratio 2.97 for CKD versus no CKD 6 months after CAS) [27], with dialysis patients being at the highest risk [28]. Despite this, Klarin et al. [29] recently reported an overall 30-day stroke and death rate of less than 3\% for CEA and CAS combined across all CKD stages, which meet the criteria endorsed by the guidelines [22, 30]. Moreover, CKD stage 3 patients with symptomatic high-grade (70-99\%) CS were shown to greatly benefit from CEA, with a relative stroke risk reduction of $82 \%$ compared to medical therapy [31]. CAS requires iodinated contrast and is associated with higher rates of major adverse cardiovascular and cerebrovascular events and twofold higher 30day mortality compared to CEA in both moderate and severe CKD $[29,32]$. Therefore, CAS becomes a viable option only in symptomatic patients at high-risk for CEA, especially if there is severe cardiac impairment [25] (Table 2).

\section{Haemorrhagic Stroke}

\section{(Resistant) Hypertension}

Hypertension is responsible for both ischaemic [33] and haemoragic stroke [34]. As a well-known CVD risk factor, high blood pressure (BP) is strongly correlated with the development of atherosclerosis and ischaemic stroke. However, since uncontrolled hypertension is the most common cause of spontaneous intracerebral haemorrhage [35], for scientific clarity we decided to discuss here the haemorrhagic stroke causality. In fact, the main interest in the "equation of $\mathrm{RH}$ " is to lower the $\mathrm{BP}$ values by all means.

As defined in the $2013 \mathrm{ESH} / \mathrm{ESC}$ guidelines, $\mathrm{RH}$ is contemplated when a therapy with 3 drugs (diuretic and 2 other antihypertensive drugs belonging to different classes at adequate doses) fails to lower BP to 140 and $90 \mathrm{~mm}$ $\mathrm{Hg}$, respectively [36].

One third of the patients with an eGFR under $45 \mathrm{~mL} /$ min and almost half of patients with a urinary albuminto-creatinine ratio $>300 \mathrm{mg} / \mathrm{g}$ have $\mathrm{RH}$, a major cause of haemorrhagic stroke among the CKD population [37].

When the addition of the "fourth line" medical therapies (e.g., aldosterone antagonists, centrally acting alphaadrenergic agonists, alpha blockers) recommended by the CKD dedicated guidelines (Kidney Disease Improving Global Outcomes, KDOQI) [38, 39] fails to efficiently lower BP, invasive procedures such as renal denervation (RD) or baroreceptor stimulation represent an alternative [36] (Table 2). Revascularization of the renal artery in patients with $\mathrm{RH}$ secondary to atherosclerotic renovascular disease is also an option (Table 2).

\section{Renal Denervation}

Even though there is limited evidence that RD controls the BP (and could have renoprotective effects: eGFR stabilization/increase and/or lower albuminuria) [40, 41], 2 major 2017 reviews $[42,43]$ questioned the benefits of $\mathrm{RD}$ on renal function and major cardiovascular events. According to the expert consensus of the ESC, RD may be performed truly for $\mathrm{RH}$ if eGFR $\geq 45 \mathrm{~mL} / \mathrm{min} / 1.73 \mathrm{~m}^{2}$ (consistent data in the more advanced stages of CKD are lacking) [44]. However, renal arteries with stenosis are not eligible for RD [44] and prophylaxis of contrast-induced nephropathy is necessary [45].

\section{Baroreflex Activation Therapy}

Even if there are not yet important studies and clear protocols, baroreflex activation therapy (BAT) could become a promising option [46] in the treatment of $\mathrm{RH}$. Particularly interesting for CKD patients is that BAT was not only shown to decrease office BP values in small prospective trials on CKD non-dialysis and dialysis patients $[47,48]$, but also to have renoprotective effects by significantly reducing proteinuria and improving eGFR [47]. BAT would be an option when $\mathrm{RD}$ is not possible or inef-
38

Cerebrovasc Dis 2018;45:33-41 DOI: $10.1159 / 000486016$
Bilha/Burlacu/Siriopol/Voroneanu/Covic 
ficient [49]. A prospective randomized controlled trial comparing the safety and efficacy of the Barostim neo BAT device versus medical therapy is currently ongoing [50].

\section{Renal Artery Stenting}

When declining kidney function impairs the efficacy of medical treatment in controlling BP or limits the use of ACEi or ARBs in atherosclerotic renovascular disease, percutaneous transluminal renal angioplasty with stenting is usually proposed as the alternative method of choice [51].

Data from RCTs failed to demonstrate a clear benefit of stenting regarding BP, renal function and cardiovascular morbidity and mortality outcomes [52-55] and therefore, renal revascularization is not endorsed by the 2017 ESC guidelines for the management of renovascular hypertension (with few specific exceptions) [30].

However, relevant gaps in evidence are represented by RCTs not addressing high-risk patients with refractory hypertension and rapidly declining kidney function. Revascularization was shown in observational studies to improve $\mathrm{BP}$ control and kidney function in CKD stages 4-5 and to have a major impact upon survival $[56,57]$. The 2017 ESC guidelines draw the attention towards the need for stratification of patients based on the estimated benefits of renal revascularization [30]. As such, percutaneous transluminal renal angioplasty with stenting seems to be most beneficial in those patients with recent high $\mathrm{BP}$ (particularly over $180 \mathrm{~mm} \mathrm{Hg}$ systolic) that is reluctant to medical therapy and prior progressive kidney function impairment $[30,58,59]$ (Table 2).

\section{Cerebral Bleeding in Antithrombotics Overdosing}

The risk of major bleeding in advanced CKD patients without anticoagulant treatment is twice as high as in the general population [60]. Even when thrombotic and haemorrhagic risks are estimated according to the guide- lines, the indication of antithrombotic treatment is solid, and the drugs are chosen and dosed accordingly; anticoagulation therapy in CKD patients can promote bleeding episodes, as these substances can accumulate or directly interfere with an already changed haemostatic system $[61,62]$. For primary prevention of cerebral haemorrhage in NOACs overdosing, there are new recommendations in the ESC guidelines for antithrombotic therapy and very good local anticoagulant reversal protocols (e.g., idarucizumab administration in dabigatran reversal [63]).

\section{Conclusions}

While CKD patients face a significantly higher risk of developing a stroke compared to the general population, the primary prevention of a cerebrovascular event in this population has significant caveats: anticoagulation is problematic especially in the late stages of $\mathrm{CKD}$, antiplatelet agents have very limited indications due to the higher bleeding risk, carotid revascularization techniques are promising but are associated with higher procedural risks in CKD patients and the medical treatment of resistant hypertension is frequently inefficient or limited by side-effects, drawing the attention towards the need for interventional procedures. Official recommendations for the CKD population are very scarce and therefore, the treatment of various comorbidities associated with stroke in CKD patients is to be done on an individualized basis. Although caution is needed when managing renal patients, refraining them from standard therapies also leaves them exposed to a considerable morbidity and mortality risk.

\section{Disclosure Statement}

The authors have no conflicts of interest to declare.

\section{References}

1 Benjamin EJ, Blaha MJ, Chiuve SE, Cushman M, Das SR, Deo R, et al: Heart disease and stroke statistics-2017 update: a report from the American heart association. Circulation 2017;135:e146-e603.

2 Power A: Stroke in dialysis and chronic kidney disease. Blood Purif 2013;36:179-183.

3 Fu J, Huang J, Lei M, Luo Z, Zhong X, Huang $\mathrm{Y}$, et al: Prevalence and impact on stroke in patients receiving maintenance hemodialy- sis versus peritoneal dialysis: a prospective observational study. PLoS One 2015;10: e0140887.

4 Thrift AG, Thayabaranathan T, Howard G, Howard VJ, Rothwell PM, Feigin VL, et al: Global stroke statistics. Int J Stroke 2017;12:13-32.

5 Chwojnicki K, Krol E, Wierucki L, Kozera G, Sobolewski P, Nyka WM, et al: Renal dysfunction in post-stroke patients. PLoS One 2016; 11:e0159775.
6 Lee M, Saver JL, Chang KH, Liao HW, Chang SC, Ovbiagele B: Low glomerular filtration rate and risk of stroke: meta-analysis. BMJ 2010;341:c4249.

7 Saran R, Robinson B, Abbott KC, Agodoa LY, Ayanian J, Bragg-Gresham J, et al: US renal data system 2016 annual data report: epidemiology of kidney disease in the United States. Am J Kidney Dis 2017;69: A7-A8. 
8 Reinecke H, Brand E, Mesters R, Schabitz WR, Fisher M, Pavenstadt H, et al: Dilemmas in the management of atrial fibrillation in chronic kidney disease. J Am Soc Nephrol 2009;20:705-711.

9 Burlacu A, Genovesi S, Ortiz A, Kanbay M, Rossignol P, Banach M, et al: The quest for equilibrium: exploring the thin red line between bleeding and ischaemic risks in the management of acute coronary syndromes in chronic kidney disease patients. Nephrol Dial Transpl 2017;32:1967-1976.

10 Kirchhof P, Benussi S, Kotecha D, Ahlsson A, Atar D, Casadei B, et al: 2016 ESC Guidelines for the management of atrial fibrillation developed in collaboration with EACTS. Eur Heart J 2016;37:2893-2962.

11 Dad T, Weiner DE: Stroke and chronic kidney disease: epidemiology, pathogenesis, and management across kidney disease stages. Semin Nephrol 2015;35:311-322.

12 Dahal K, Kunwar S, Rijal J, Schulman P, Lee $\mathrm{J}$ : Stroke, major bleeding, and mortality outcomes in warfarin users with atrial fibrillation and chronic kidney disease: a meta-analysis of observational studies. Chest 2016;149:951959.

13 Harenberg J, Hentschel VA, Du S, Zolfaghari S, Kramer R, Weiss C, et al: Anticoagulation in patients with impaired renal function and with haemodialysis. Anticoagulant effects, efficacy, safety, therapeutic options. Hamostaseologie 2015;35:77-83.

14 Fang MC, Go AS, Chang Y, Borowsky LH, Pomernacki NK, Udaltsova $\mathrm{N}$, et al: A new risk scheme to predict warfarin-associated hemorrhage: the ATRIA (Anticoagulation and Risk Factors in Atrial Fibrillation) Study J Am Coll Cardiol 2011;58: 395-401.

15 Szummer K, Gasparini A, Eliasson S, Arnlov J, Qureshi AR, Barany P, et al: Time in therapeutic range and outcomes after warfarin initiation in newly diagnosed atrial fibrillation patients with renal dysfunction. J Am Heart Assoc 2017;6:e004925.

16 Del-Carpio Munoz F, Gharacholou SM, Munger TM, Friedman PA, Asirvatham SJ, Packer DL, et al: Meta-analysis of renal function on the safety and efficacy of novel oral anticoagulants for atrial fibrillation. Am J Cardiol 2016;117:69-75.

17 Bansal VK, Herzog CA, Sarnak MJ, Choi MJ, Mehta R, Jaar BG, et al: Oral anticoagulants to prevent stroke in nonvalvular atrial fibrillation in patients with CKD stage 5D: an NKFKDOQI controversies report. Am J Kidney Dis 2017;70:859-868.

18 Workgroup KD: KDOQI clinical practice guidelines for cardiovascular disease in dialysis patients. Am J Kidney Dis 2005;45:S1S153.

19 Dias C, Moore KT, Murphy J, Ariyawansa J, Smith W, Mills RM, et al: Pharmacokinetics, pharmacodynamics, and safety of single-dose rivaroxaban in chronic hemodialysis. Am J Nephrol 2016;43:229-236.
20 Reinecke H, Engelbertz C, Schabitz WR: Preventing stroke in patients with chronic kidney disease and atrial fibrillation: benefit and risks of old and new oral anticoagulants. Stroke 2013;44:2935-2941.

21 Pelisek J, Hahntow IN, Eckstein HH, Ockert S, Reeps C, Heider P, et al: Impact of chronic kidney disease on carotid plaque vulnerability. J Vasc Surg 2011;54:1643-1649.

22 Meschia JF, Bushnell C, Boden-Albala B, Braun LT, Bravata DM, Chaturvedi S, et al: Guidelines for the primary prevention of stroke: a statement for healthcare professionals from the American Heart Association/ American Stroke Association. Stroke 2014;45: 3754-3832.

23 Stevens PE, Levin A, Kidney Disease: Improving Global Outcomes Chronic Kidney Disease Guideline Development Work Group Members: Evaluation and management of chronic kidney disease: synopsis of the kidney disease: improving global outcomes 2012 clinical practice guideline. Ann Intern Med 2013;158:825-830.

24 Palmer SC, Di Micco L, Razavian M, Craig JC, Perkovic V, Pellegrini F, et al: Antiplatelet agents for chronic kidney disease. Cochrane Database Syst Rev 2013;2:CD008834.

25 Ricotta JJ, Aburahma A, Ascher E, Eskandari M, Faries P, Lal BK, et al: Updated society for vascular surgery guidelines for management of extracranial carotid disease. J Vasc Surg 2011;54:e1-e31.

26 Tarakji A, McConaughy A, Nicholas GG: The risk of carotid endarterectomy in patients with chronic renal insufficiency. Curr Surg 2006;63:326-329.

27 Saw J, Gurm HS, Fathi RB, Bhatt DL, AbouChebl A, Bajzer C, et al: Effect of chronic kidney disease on outcomes after carotid artery stenting. Am J Cardiol 2004;94:1093-1096.

28 Adil MM, Saeed F, Chaudhary SA, Malik A, Qureshi AI: Comparative outcomes of carotid artery stent placement and carotid endarterectomy in patients with chronic kidney disease and end-stage renal disease. J Stroke Cerebrovasc Dis 2016;25:1721-1727.

29 Klarin D, Lancaster RT, Ergul E, Bertges D, Goodney P, Schermerhorn ML, et al: Perioperative and long-term impact of chronic kidney disease on carotid artery interventions. J Vasc Surg 2016;64:1295-1302.

30 Aboyans V, Ricco JB, Bartelink MEL, Bjorck M, Brodmann M, et al: 2017 ESC guidelines on the diagnosis and treatment of peripheral arterial diseases, in collaboration with the European Society for Vascular Surgery (ESVS). Eur J Vasc Endovasc Surg 2017, Epub ahead of print.

31 Mathew A, Eliasziw M, Devereaux PJ, Merino JG, Barnett HJ, Garg AX, et al: Carotid endarterectomy benefits patients with CKD and symptomatic high-grade stenosis. J Am Soc Nephrol 2010;21:145-152.

32 Lima F V, Yen TY, Butler J, Yang J, Xu J, Gruberg L: Impact of chronic kidney disease in patients undergoing percutaneous or surgical carotid artery revascularization: insights of the healthcare cost and utilization Project's National Inpatient Sample. Cardiovasc Revasc Med 2016;17:560-565.

33 Hung CY, Wang KY, Wu TJ, Hsieh YC, Huang JL, Loh EW, et al: Resistant hypertension, patient characteristics, and risk of stroke. PLoS One 2014;9:e104362.

34 Dandapani BK, Suzuki S, Kelley RE, ReyesIglesias Y, Duncan RC: Relation between blood pressure and outcome in intracerebral hemorrhage. Stroke 1995;26:21-24.

35 Brott T, Thalinger K, Hertzberg V: Hypertension as a risk factor for spontaneous intracerebral hemorrhage. Stroke 1986;17:10781083.

36 Mancia G, Fagard R, Narkiewicz K, Redon J, Zanchetti A, Bohm M, et al: 2013 ESH/ESC guidelines for the management of arterial hypertension: the Task Force for the Management of Arterial Hypertension of the European Society of Hypertension (ESH) and of the European Society of Cardiology (ESC). Eur Hear J 2013;34:2159-2219.

37 Tanner RM, Calhoun DA, Bell EK, Bowling $\mathrm{CB}$, Gutierrez OM, Irvin MR, et al: Prevalence of apparent treatment-resistant hypertension among individuals with CKD. Clin J Am Soc Nephrol 2013;8:1583-1590.

38 Wheeler DC, Becker GJ: Summary of KDIGO guideline. What do we really know about management of blood pressure in patients with chronic kidney disease? Kidney Int 2013; 83:377-383.

39 Kidney Disease Outcomes Quality Initiative (K/DOQI): K/DOQI clinical practice guidelines on hypertension and antihypertensive agents in chronic kidney disease. Am J Kidney Dis 2004;43:S1-S290.

40 Persu A, Jin Y, Azizi M, Baelen M, Volz S, Elvan A, et al: Blood pressure changes after renal denervation at 10 European expert centers. J Hum Hypertens 2014;28:150156.

41 Hering D, Marusic P, Duval J, Sata Y, Head GA, Denton KM, et al: Effect of renal denervation on kidney function in patients with chronic kidney disease. Int J Cardiol 2017; 232:93-97.

42 Sanders MF, Reitsma JB, Morpey M, Gremmels H, Bots ML, Pisano A, et al: Renal safety of catheter-based renal denervation: systematic review and meta-analysis. Nephrol Dial Transplant 2017;32:1440-1447.

43 Coppolino G, Pisano A, Rivoli L, Bolignano D: Renal denervation for resistant hypertension. Cochrane Database Syst Rev 2017; 2:CD011499.

44 Mahfoud F, Luscher TF, Andersson B, Baumgartner I, Cifkova R, Dimario C, et al: Expert consensus document from the European Society of Cardiology on catheter-based renal denervation. Eur Heart J 2013;34:2149 2157.

45 Veelken R, Schmieder RE: Renal denervation - implications for chronic kidney disease. Nat Rev Nephrol 2014;10:305-313. 
46 Yoruk A, Bisognano JD, Gassler JP: Baroreceptor stimulation for resistant hypertension. Am J Hypertens 2016;29:1319-1324.

47 Wallbach M, Lehnig LY, Schroer C, Hasenfuss G, Muller GA, Wachter R, et al: Impact of baroreflex activation therapy on renal function - a pilot study. Am J Nephrol 2014;40: 371-380.

48 Beige J, Koziolek MJ, Hennig G, Hamza A, Wendt R, Muller GA, et al: Baroreflex activation therapy in patients with end-stage renal failure: proof of concept. J Hypertens 2015;33: 2344-2349.

49 Hoppe UC, Brandt MC, Wachter R, Beige J, Rump LC, Kroon AA, et al: Minimally invasive system for baroreflex activation therapy chronically lowers blood pressure with pacemaker-like safety profile: results from the Barostim neo trial. J Am Soc Hypertens 2012; 6:270-276.

50 CVRx I: BAROSTIM NEO HTN Pivotal Trial. 2017. https://clinicaltrials.gov/ct2/show/ NCT01679132.

51 Herrmann SM, Saad A, Textor SC: Management of atherosclerotic renovascular disease after Cardiovascular Outcomes in Renal Atherosclerotic Lesions (CORAL). Nephrol Dial Transplant 2015;30:366-375.

52 Bax L, Woittiez AJ, Kouwenberg HJ, Mali WP, Buskens E, Beek FJ, et al: Stent placement in patients with atherosclerotic renal artery stenosis and impaired renal function: a randomized trial. Ann Intern Med 2009;150:840-848.

53 ASTRAL Investigators, Wheatley $\mathrm{K}$, Ives $\mathrm{N}$, Gray R, Kalra PA, Moss JG, et al: Revascularization versus medical therapy for renal-artery stenosis. N Engl J Med 2009;361:19531962.

54 Cooper CJ, Murphy TP, Cutlip DE, Jamerson K, Henrich W, Reid DM, et al: Stenting and medical therapy for atherosclerotic renal-artery stenosis. N Engl J Med 2014;370:13-22.

55 Misra S, Khosla A, Allred J, Harmsen WS, Textor SC, McKusick MA: Mortality and renal replacement therapy after renal artery stent placement for atherosclerotic renovascular disease. J Vasc Interv Radiol 2016;27: 1215-1224.

56 Kalra PA, Chrysochou C, Green D, Cheung CM, Khavandi K, Sixt S, et al: The benefit of renal artery stenting in patients with atheromatous renovascular disease and advanced chronic kidney disease. Catheter Cardiovasc Interv 2010;75:1-10.

57 Herrmann SM, Textor SC: Current concepts in the treatment of renovascular Hypertension. Am J Hypertens 2017, Epub ahead of print.

58 Jaff MR, Bates M, Sullivan T, Popma J, Gao X, Zaugg $M$, et al: Significant reduction in systolic blood pressure following renal artery stenting in patients with uncontrolled hypertension: results from the HERCULES trial. Catheter Cardiovasc Interv 2012;80:343-350.

59 Anderson JL, Halperin JL, Albert NM, Bozkurt B, Brindis RG, Curtis LH, et al: Management of patients with peripheral artery disease (compilation of 2005 and 2011 ACCF/ AHA guideline recommendations): a report of the American College of Cardiology Foundation/American Heart Association Task Force on Practice Guidelines. Circulation 2013;127:1425-1443.

60 Parikh AM, Spencer FA, Lessard D, Emery C, Baylin A, Linkletter C, et al: Venous thromboembolism in patients with reduced estimated GFR: a population-based perspective. Am J Kidney Dis 2011;58:746-755.

61 Lutz J, Jurk K, Schinzel H: Direct oral anticoagulants in patients with chronic kidney disease: patient selection and special considerations. Int J Nephrol Renovasc Dis 2017;10: 135-143.

62 Dager WE, Kiser TH: Systemic anticoagulation considerations in chronic kidney disease. Adv Chronic Kidney Dis 2010;17:420-427

63 UW Medicine: Guidelines for Revearsal of Anticoagulants, 2016. https://depts.washington.edu/anticoag/home/sites/default/files/ GUIDELINES FOR REVERSAL OF ANTICOAGULANTS.pdf. 